\title{
Surgical Techniques for Correcting Aberrant Frenal Attachment: A Clinical Review
}

\author{
C. S. Baiju ${ }^{1}$ Karuna Joshi ${ }^{1}$ Ria Virmani ${ }^{1}$ Gunjan Gupta ${ }^{1}$ Pawandeep Kaur ${ }^{1}$ \\ ${ }^{1}$ Department of Periodontics and Oral Implantology, Sudha Rustagi \\ College of Dental Sciences, Faridabad, Haryana, India \\ Dent J Adv Stud 2021;9:111-115. \\ Address for correspondence Karuna Joshi, MDS, Department of \\ Periodontics and Oral Implantology, Sudha Rustagi College of Dental \\ Sciences, Faridabad, Haryana 121002, India \\ (e-mail: karunajoshi1903@gmail.com).
}

\begin{abstract}
Keywords

- frenum

- frenectomy

- frenotomy

- scalpel techniques

Frenum is a fold of mucous membrane, usually with enclosed muscle fibers, which attaches the lips and cheeks to the alveolar mucosa and/or gingival and underlying periosteum. Different types of frenal attachments have been observed and classified. Frenum with abnormal attachments may lead to mucogingival problems while hampering gingival health, as they cause an interference in the plaque control or may create a muscle pull. This condition may require management that can be usually performed with frenectomy and frenotomy procedures. Frenectomy is the complete removal of the frenum, while frenotomy is the incision and relocation of the frenal attachment. The present article is a compilation and review of a series of clinical cases of frenal excision through different surgical approaches.
\end{abstract}

\section{Introduction}

A frenum is a fold of mucous membrane, maybe with enclosed muscle fibers, which attaches the lips and cheeks to the alveolar mucosa and/or gingiva and underlying periosteum. ${ }^{1}$ It can be categorized as long and thin or short and broad. ${ }^{2}$ The maxillary and mandibular labial frenum are commonly attached below the respective alveolar crests. ${ }^{3}$ Knox and Young in their histological examination observed the presence of the epithelium and muscle fibers in the labial frenum (orbicularis oris-horizontal bands and oblique fibers). While Henry, Levin and Tsaknis found an appreciable presence of dense collagenous tissue and elastic fibers but a lack of muscle fibers in the frenum. ${ }^{4}$ It has been noted that the connective tissue between the inferior portion of the incisivus labii superioris (ILS) muscle conformed to the inferior labial frenulum and the extent of the inferior part of the ILS correlated to the folds of the upper alveolar mucosa. ${ }^{5}$
Mirko et al classified it, depending upon the extension of attachment of fibers ${ }^{6}$ :

a. mucosal attachment of the frenum, insertio in mucosam, means an attachment of the frenum to the mucogingival junction.

b. gingival attachment, insertio in mucosam fixam, stands for an attachment of the frenum to the attached gingiva.

c. papillary attachment, insertio in papillam, means an attachment of the frenum to the papilla.

d. papillary penetrating attachment is in those cases when the attachment of the frenum passes right up to the papilla while inserting in attached gingiva.

A frenum encroaching on the gingival margin may compromise the status of gingival health, either due to an obstruction in the plaque control or due to a muscle pull. These hygiene problems are usually more pronounced in the mandibular anterior areas. ${ }^{7}$ published online October 18, 2021
DOI https://doi.org/ 10.1055/s-0041-1736263. ISSN 2321-1482. (c) 2021. Bhojia Dental College and Hospital affiliated to Himachal Pradesh University. All rights reserved.

This is an open access article published by Thieme under the terms of the Creative Commons Attribution-NonDerivative-NonCommercial-License, permitting copying and reproduction so long as the original work is given appropriate credit. Contents may not be used for commercial purposes, or adapted, remixed, transformed or built upon. (https://creativecommons.org/ licenses/by-nc-nd/4.0/)

Thieme Medical and Scientific Publishers Pvt. Ltd., A-12, 2nd Floor, Sector 2, Noida-201301 UP, India 
Visually, detection of abnormal frenum is done by employing tension over it to notice the movement of papillary tip or the production of blanching due to ischemia of the segment. Usually, papillary and papilla penetrating frena are found to be pathological. These are accompanied by loss of papilla, gingival recession, midline diastema, difficulty in oral hygiene maintenance, malalignment of teeth, and impairment of the denture fit or retention. ${ }^{8}$ Since the basic function of the frenum is to maintain stability between the growing bones and the musculature of the lip, presence of aberrant frenal attachment can modify the movement of these structures and may have an effect on the position of jaws and arrangement of dentition. ${ }^{9}$

According to Olivi et al, ${ }^{10}$ clinical indications for frenum removal include the following:

i. Anomalous frenum associated with inflamed gingiva, resulting from poor oral hygiene.

ii. Anomalous frenum associated with gingival recession.

iii. Maxillary frenum associated with a diastema after complete eruption of the permanent canines.

iv. Abnormal and/or anomalous maxillary frenum (class III or IV), resulting in the presence of a diastema during mixed dentition.

v. Anomalous mandibular frenum with high insertion, causing the onset of gingival recession.

Thus, management of such frenum may be usually performed with frenectomy and frenotomy procedures. Frenotomy is the simple excisional release of frenulum from the apex of its insertion to its base and down to the alveolar process, whereas frenectomy is the complete removal of frenulum, including its attachment to the underlying alveolar process. ${ }^{11}$ These procedures can be accomplished either by routine scalpel techniques, which include the conventional technique, Millers' technique, Z plasty and V-Y plasty, or by using electrocautery and lasers. This article is a review on different scalpel techniques as performed on various cases that reported for correction of aberrant frenal attachments.

\section{Conventional Frenectomy}

A male patient of 34 years reported to the Department of Periodontology with the main complaint of receding gums and spacing in the upper front region of the teeth. On examination, it was found that there was papilla penetrating type of frenal attachment (-Fig. 1A), presence of gingival recession, and a reported difficulty in maintenance of oral hygiene. While performing the tension test, a constant frenal pull was noted. Conventional frenectomy technique was performed for the given case.

\section{Technique $^{1}$}

After anesthetizing the surgical area locally, the lip was extended by the assistant, and the frenum was held with a hemostat by engaging it into the depth of the vestibule. The first incision was placed on the upward segment of the hemostat while extending it beyond the tip. A similar incision was made along the undersurface of the hemostat. The triangular portion of the frenum was resected and removed,

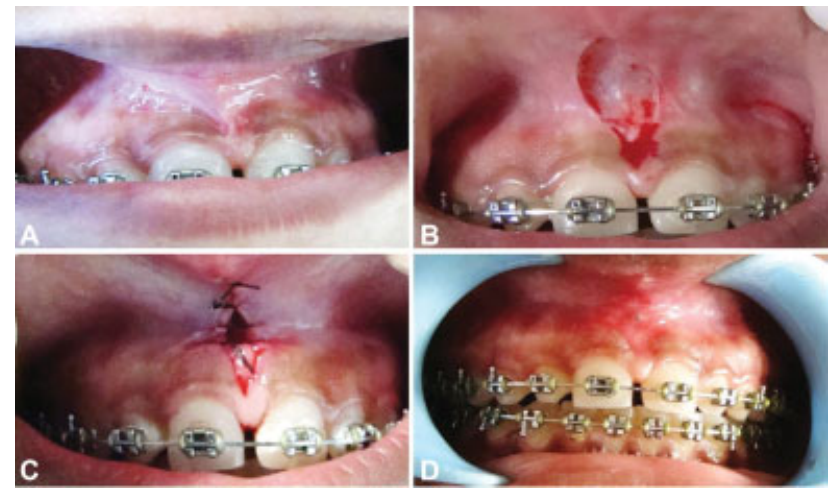

Fig. 1 (A) Preoperative papilla penetrating type of frenal attachment. (B) The diamond-shaped incision and excision of frenum. (C) Approximation with 3-0 black silk suture. (D) One-month postoperative of conventional frenectomy.

exposing the underlying fibrous attachment to the bone. Horizontal incision was given to separate the fibers following their blunt dissection from the bone (-Fig. 1B). For effortless approximation, the diamond-shaped wound edges were undermined slightly. Approximation was done without creating tension and only on the mucosal extent of incision by using 3-0 black silk with interrupted sutures (-Fig. 1C, D).

\section{Miller's Frenectomy}

A 15-year-old patient undergoing orthodontic therapy for closure of midline diastema was referred to the Department of Periodontics for management of papillary frenum (-Fig. 2A). Frenectomy was considered as a preventive measure, since relapse separation of the teeth has been reported in the case of orthodontic closure of diastema without excision of associated frena. ${ }^{13}$ For such cases, the frenal excision can be performed either before or after the central incisors have been approximated by appliance therapy. However, it has been observed that surgical excision of frenum can lead to scar formation, which can cause a difficulty in movement of teeth. ${ }^{14}$ Henceforth, it is suggested that frenectomy is performed after the completion of orthodontic therapy. According to Miller, the ideal timing for performing the surgery is after the orthodontic movement is complete and approximately 6 weeks before the fixed
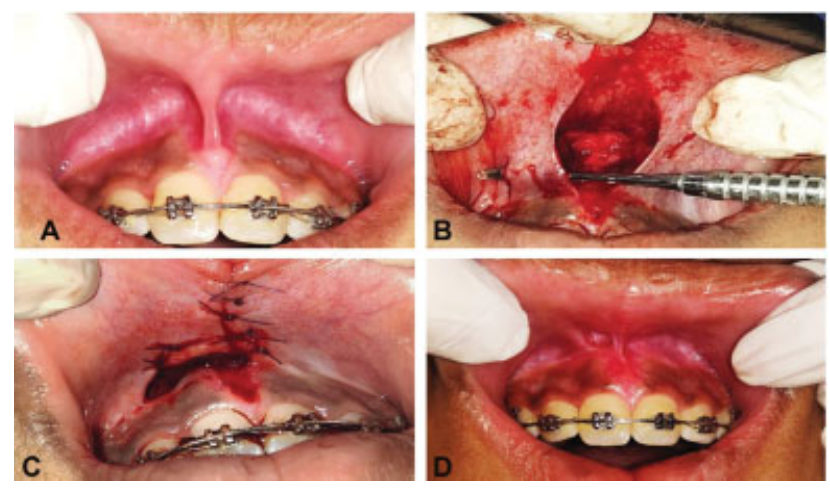

Fig. 2 (A) Papillary type of frenal attachment. (B) Frenum excised, lateral pedicle graft obtained. (C) Graft sutured across the midline. (D) One-month postoperative of Millers technique. 
appliances are removed. ${ }^{15}$ Therefore, the present case was performed using slight modification in Millers' technique.

\section{Technique $^{16}$}

The surgical area was anesthetized with local infiltration, and a horizontal incision was made to separate the frenulum from the interdental papilla. Care was taken to ensure that the frenum was completely excised with no remnants remaining on the undersurface. A lateral pedicle graft was then obtained with vertical parallel incision, which was done on the mesial side of the lateral incisors. The pedicle graft was undermined, and a horizontal incision was given (-Fig. 2B). The obtained laterally positioned pedicle graft was raised, mobilized mesially, and secured using 4-0 absorbable sutures to achieve primary closure across the midline (-Fig. 2C). Periodontal dressing was given on the surgical area. Dressing and remaining sutures were removed 15 days later. An uneventful healing of attached gingiva with no loss of the interdental papilla was observed (-Fig. 2D).

\section{V-Y Plasty}

A female patient of 38 years reported to the Department of Periodontology with a primary complaint of receding gums in the lower front region of the jaw. On clinical examination, papillary type of frenal attachment was noted ( $\mathbf{F i g . ~ 3 A ) . ~}$ During the phase 1 therapy, it was observed that the patient was unable to maintain oral hygiene due to the constant frenal pull. This case was considered for V-Y plasty surgical procedure.

\section{Technique $^{15,18}$}

After extending the lip, frenum was engaged with a hemostat, and a V-shaped incision was formed on the undersurface of the frenal attachment ( - Fig. 3B). The frenum was relocated at an apical position, and while suturing with
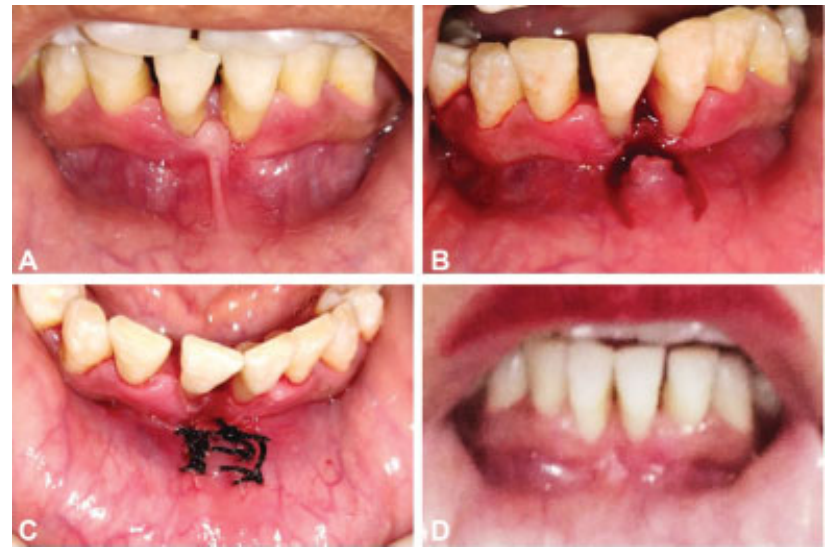

Fig. 3 (A) Preop papillary type of frenal attachment. (B) Frenum incised by $V$-shaped incision. (C) V-shaped incision sutured in the form of $Y$. (D) One-month postoperative of V-Y plasty.

3-0 silk, the V-shaped incision was converted into a $\mathrm{Y}$ (-Fig. 3C, D).

\section{Z-Plasty}

A 45-year-old male reported to the Department of Prosthodontics with a chief complaint of missing upper front teeth. However, upon clinically evaluation, it was noted that the denture placement, stability, and retention would have been compromised by the presence of thick broad fibrous frenal attachment ( $\mathbf{- F i g . ~ 4 A )}$ ), which was located near the crest of the residual ridge. Therefore, the patient was referred to the Department of Periodontology for management of such frenal attachment.

The case was attempted with Z-plasty technique, since it is indicated when there is hypertrophy of the frenum with a low insertion, which is associated with an interincisor diastema.
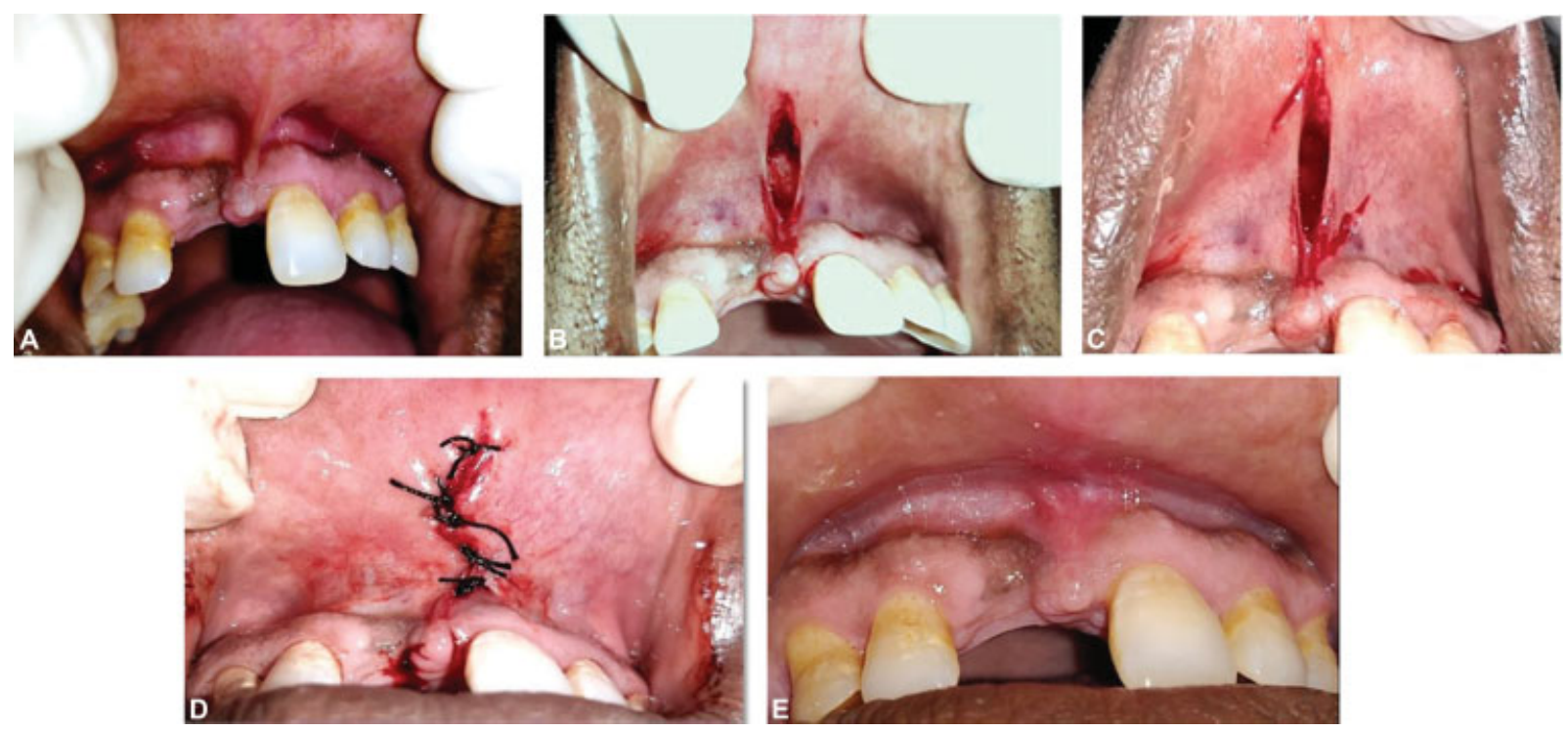

Fig. 4 (A) Papilla penetrating type of frenal attachment. (B) Incision and removal of excised frenum. (C) Incision given at both ends of the frenum to obtain two triangular flaps. (D) Flaps transposed across the midline and sutured in the form of Z. (E) Two-week postoperative of Z-plasty. 
Technique $e^{17,18}$

After locally infiltrating the surgical area, an incision was made across the base of the frenum at its attachment to the incisive papilla. Incision was made at the most inferior part of the frenum in an upward direction. The dissection was carried down to the periosteum, and the incision was then extended along both sides of the frenum to its attachment on the labial mucosa, following the removal of frenum and excess fibrous tissue across the alveolar ridge between the teeth. All the soft-tissue barriers were removed ( - Fig. 4B). Thereafter, two lateral incisions or limbs were made at angulation of $60^{\circ}$ at the top and bottom of the first incision, creating two triangular flaps of equal size and shape (-Fig. 4C). The resulting double rotation flaps obtained were $1 \mathrm{~cm}$ long. Before repositioning the mucosal flaps, it was made sure that all fibrous adhesions to the periosteum were divided by means of blunt dissection. The resultant flaps were mobilized and transposed perpendicularly to close the vertical incisions horizontally. Transpositioning of the flaps redistributes tension on the wound and changes the direction of central limb. The middle bar of the $Z$ was placed directly over the midline of the frenum. The rotated flaps were stabilized by giving anchor sutures at two flap tips by 3-0 braided black silk sutures. For approximation of diagonal lines, additional simple interrupted sutures were placed (-Fig. 4D, E). Prosthesis was fabricated 1 month later.

\section{Discussion}

Frena are triangle-shaped folds found in the maxillary and mandibular alveolar mucosa. They are located between the central incisors and canine premolar area. ${ }^{19}$ Abnormal attachment can cause mucogingival problems. A frenum can be considered pathogenic when there may be an apparent lack of width of attached gingiva along the midline or the interdental papilla shifts when the frenum is extended. Nevins stated that a shallow vestibule impedes oral cleansing, and that the frenum must be carefully considered as a threat to long-term periodontal health when superimposed on a shallow vestibule. ${ }^{20,21}$ For achieving the desired outcome, removal of such pathogenic frenum with proper technique selection is required. The widely followed procedure remains the classical technique proposed by Archer and Kruger. This technique leads to a complete excision of the frenum, interdental tissue and palatine papilla and also leads to exposure of the underlying alveolar bone. However, the scarring produced may foster periodontal problems and an unaesthetic appearance, but this approach was advocated to assure the removal of muscle fibers, connecting the orbicularis oris with palatine papilla and was utilized as the only technique to prevent reopening of the diastema. However, it often resulted in loss of interdental papilla between the maxillary incisors. Thus, in 1985, Miller established a surgical technique that combined frenectomy with a laterally positioned pedicle graft. This resulted in less scar formation, and better esthetic and functional results were obtained. ${ }^{15}$

Frenotomy, on the other hand, represents a gentler operation. With frenectomy, the attachment of the frenum to gingiva and periosteum is served, and the insertion of the frenum is relocated several millimeters up on the alveolar mucosa. ${ }^{22}$ For this technique, simple modification of V-rhomboplasty can be considered. However, it may fail to provide sufficiently good results due to the inefficient primary closure at the center, thus causing a secondary intention healing at the exposed wound. This may create an esthetic concern in cases of a high smile line, as it can lead to an exposure of anterior gingiva. The Z-plasty technique was found to be ideal for a broad, thick hypertrophic frenum with a low insertion, which was associated with an interincisor diastema and a short vestibule. It is achieved by removal of the fibrous band and the vertical lengthening of the vestibule.

It has been observed that frenectomy/frenotomy is a frequently performed procedure with varying intent. Therefore, knowledge and utilization of different techniques should be based on the character, type of frenal attachment, and objective of correction of abnormal frenum to achieve pertinent functional and esthetic outcomes.

\section{Conflict of Interest}

None declared.

\section{References}

1 Takei HH, Azzi RR, Han T. Periodontal plastic and esthetic surgery. Newmann MG, Takei HH, Klokkevold PR, Carranza FA, eds. Carranza's Clinical Periodontology. India: Elsevier Inc.; 2002

2 Huang WJ, Creath CJ. The midline diastema: a review of its etiology and treatment. Pediatr Dent 1995;17(03):171-179

3 Standring S, ed. Gray's Anatomy E-Book: The Anatomical Basis of Clinical Practice. Edinburgh: Elsevier Health Sciences; 2015

4 Gartner LP, Schein D. The superior labial frenum: a histologic observation. Quintessence Int 1991;22(06):443-445

5 Hur MS, Kim HJ, Choi BY, Hu KS, Kim HJ, Lee KS. Morphology of the mentalis muscle and its relationship with the orbicularis oris and incisivus labii inferioris muscles. J Craniofac Surg 2013;24(02): 602-604

6 Mirko P, Miroslav S, Lubor M. Significance of the labial frenum attachment in periodontal disease in man. Part I. Classification and epidemiology of the labial frenum attachment. J Periodontol 1974;45(12):891-894

7 Sharma P, Salaria SK, Gowda RK, Ahuja S, Joshi S, Bansal DK. Frenectomy-a brief review. Int J Contemporary Med Res 2014; 1:37-52

8 Priyanka M, Sruthi R, Ramakrishnan T, Emmadi P, Ambalavanan N. An overview of frenal attachments. J Indian Soc Periodontol 2013; 17(01):12-15

9 Srinivasan B, Chitharanjan AB. Skeletal and dental characteristics in subjects with ankyloglossia. Prog Orthod 2013;14(01): 44

10 Olivi G, Chaumanet G, Genovese MD, Beneduce C, Andreana S. Er,Cr:YSGG laser labial frenectomy: a clinical retrospective evaluation of 156 consecutive cases. Gen Dent 2010;58(03): e126-e133

11 Cohen ES. Atlas of Cosmetic and Reconstructive Periodontal Surgery. 3rd ed. Hamilton: Bc Decker; 2007

12 Proffit WR, Fields HW, Larson B, Sarver DM. Contemporary Orthodontics-e-book. St. Louis, MO: Elsevier Health Sciences; 2018

13 Edwards JG. The diastema, the frenum, the frenectomy: a clinical study. Am J Orthod 1977;71(05):489-508

14 West EE. Diastema-a cause for concern. Dent Clin North Am 1968July:425-434 
15 Devishree SK, Gujjari SK, Shubhashini PV. Frenectomy: a review with the reports of surgical techniques. J Clin Diagn Res 2012;6 (09):1587-1592

16 Miller PD Jr. The frenectomy combined with a laterally positioned pedicle graft. Functional and esthetic considerations. J Periodontol 1985;56(02):102-106

17 Barot V, Brahmbhatt J. Z-plasty: an esthetic eraser for labial frenum. Univ Res J Dent 2016;6(01):48

18 Geoffrey L. Howe's surgical aids to denture construction. In: Minor Oral Surgery: 3rd ed. Bristol: J. Wright \& Sons; 1985
19 Hussain ST, Surendranath P. Frenectomy-A case review. Eur J Mol Clin Med 2020;7(08):1853-1855

20 Nevins M. Attached gingiva-mucogingival therapy and restorative dentistry. Int J Periodontics Restorative Dent 1986;6(04):9-27

21 Nevins M, Cappetta EG. Mucogingival surgery: The rationale and long term results. In: Nevins M, Mellonig JT, Cappetta G, eds. Periodontal Therapy: Clinical Approaches and Evidence Of Success. Chicago: Quintessence Publishing; 1998

22 Lindhe J, Lang NP, Karring T, eds. Clinical Periodontology and Implant Dentistry. Oxford: Blackwell Munksgaard; 2008 